\title{
TO SHIFT OR NOT TO SHIFT? DETERMINANTS AND CONSEQUENCES OF PHASE SHIFTING ON JUSTICE JUDGMENTS
}

\author{
GUILLAUME SOENEN \\ TESSA MELKONIAN \\ Emlyon Business School \\ MAUREEN L. AMBROSE \\ University of Central Florida
}

\begin{abstract}
Building on fairness heuristic theory and dual-process theories of cognition, we examine individuals' perceptions of phase shifting. We define phase shifting as an individual perception that triggers a shift from type 1 to type 2 cognitive processes resulting in the reevaluation of justice judgments. In a longitudinal study of a merger, we empirically test the influence of phase-shifting perceptions on justice judgments, and we identify antecedents of phase-shifting perceptions. We find employees' perceptions of the change as a phase-shifting event moderates the relationship between overall justice judgments prior to change (time 1), and subsequent assessments of justice six months later (time 2). We study three situational antecedents (i.e., magnitude of change, managerial exemplarity, and coworker support for change) and one individual antecedent (i.e., dispositional resistance to change) of phase-shifting perceptions. The four hypothesized antecedents together predict $74 \%$ of employees' perceptions of the merger as a phase-shifting event. Implications for research and practice regarding organizational justice and organizational change are discussed.
\end{abstract}

Justice judgments impact a broad range of workrelated and health outcomes (for a review, see Colquitt et al., 2013; Elovainio, Kivimäki, \& Vahtera, 2002). Understanding how such judgments are formed, and may evolve over time, is therefore an important endeavor for research and practice alike (Hausknecht, Sturman, \& Roberson, 2011; Holtz \& Harold, 2009). A dominant perspective for understanding how justice judgments are formed and evolve in organizations is fairness heuristic theory (FHT) (Colquitt, Greenberg, \& Zapata-Phelan, 2005; Lind, 2001; Van den Bos, Lind, \& Wilke, 2001), and a large number of studies have supported it (Colquitt, Noe, \& Jackson, 2002; Hausknecht et al., 2011; Jones \& Martens, 2009; Jones \& Skarlicki, 2005; Jones \& Skarlicki, 2013). However, a central aspect of FHT — the effect of phase-shifting events (i.e., events that trigger individuals to reevaluate and revise their justice judgments) — has received limited attention, and empirical work on phase shifting has only studied it indirectly (see Fortin, 2008; Jones \& Skarlicki, 2013). In this manuscript, we directly

We are thankful to the APICIL Company and the Gordon J. Barnett Foundation for their support of this research. assess individuals' perceptions of phase shifting, the consequences of these perceptions, and their antecedents. Following FHT, we focus on phase shifting as the cognitive mechanism that leads to changes in individuals' justice judgments. Additionally, we integrate research on FHT and dual process models of cognition to identify antecedents of employees' phase-shifting perceptions. Specifically, we examine phase-shifting consequences and antecedents in a change context. We argue that phase shifting may or may not occur in the face of organizational change, and whether it does is predictable from a number of situational and individual variables.

Our paper has two distinct, but related foci: we examine both the consequences of phase-shifting perceptions and the antecedents of phase-shifting perceptions. The first focus of our paper is the examination of predictions from FHT about phaseshifting perceptions. Specifically, we examine the proposition from FHT that an organizational change (e.g., a merger) triggers phase-shifting perceptions, which, as predicted by the theory, influence justice judgments. That is, phase-shifting perceptions moderate the relationship between existing and 
subsequent overall justice judgments. Empirical examination of this fundamental aspect of FHT is needed for a fuller understanding of how justice judgments evolve over time.

In the second part of the paper, we propose that phase shifting can be predicted by a number of situational and individual variables. We draw on dualprocess models of cognition (Evans, 2006; Strack \& Deutsch, 2004) to identify antecedents of employees' phase-shifting perceptions. Dual-process models of cognition argue that two distinct cognitive information processes are at play for human beings: one intuitive (occurs automatically, almost preconsciously and based on associations), and one analytic (occurs only optionally, when motivation and cognitive resources are available, and based on experience). FHT can be conceptualized as a specific case of dual-process theory (Cropanzano \& Rupp, 2003; Skarlicki \& Rupp, 2010). Notably, dual-process theories suggest that both situational and dispositional antecedents influence the likelihood of the shift from the intuitive to the analytic process (Stanovich, 2009, 2011; Strack \& Deutsch, 2004; Thompson, Turner, \& Pennycook, 2011). We utilize this theorizing to identify antecedents of phase shifting. Specifically, in the context of a merger, we examine how three change-related situational characteristics (i.e., magnitude of change, managerial exemplarity, and coworker support for change) and one individual characteristic (i.e., dispositional resistance to change [DRTC]) influence whether employees will perceive the change as a phase-shifting event.

This study contributes both theoretically and empirically to the justice literature. Theoretically, this study expands our understanding of organizational justice by extending FHT in three ways. First, we establish the perceptual nature of phase shifting. Extant research on FHT conceptualizes phase shifting as an attribute of the event; the event either elicits a phase shift, or it does not (see theoretical work by Jones \& Skarlicki, 2013 for an exception to this approach). However, we suggest that individuals may vary in their perceptions of an event as phase shifting. We show that phase-shift perceptions vary at the individual level, and it is the perception of an event as phase shifting that influences subsequent justice judgments. We demonstrate that to understand phase shifting, researchers must understand employees' perceptions of the event.

Second, extant research has provided only general guidance concerning antecedents of phase shifting (Lind, 2001; Van den Bos \& Lind, 2002). Building on dual-process theories, we identify factors that are likely to be associated with phase shifting. Specifically, we test individual and situational change-related antecedents of phase-shifting perceptions.

Third, we explicitly conceptualize FHT as a dualprocess theory focused on justice judgments. Recognizing the relationship between FHT and dual-process theories expands the paths justice researchers might explore in their quest to understand justice judgments and their influence on decisions. We utilize dual-process theories as a guide for identifying antecedents of phase-shifting perceptions. However, explicating the relationship between FHT and dual-process theories also provides other avenues for investigating how and when individuals utilize justice judgments.

Empirically, we provide the first explicit test of a core assumption of FHT (Lind, 2001) regarding the influence of phase shifting on experienced overall justice and anticipatory justice (i.e., how fairly employees expect to be treated during the change). We examine whether phase shifting influences the dynamics of justice longitudinally. Specifically, consistent with FHT, we demonstrate that when individuals perceive an event as a phase shift, they reevaluate their overall justice judgments, and their previous overall justice judgment is no longer related to their beliefs about how fairly they will be treated in the future.

Our results also contribute to research on change management and, in particular, mergers and acquisitions (M\&As) post-integration management, by detailing the conditions that lead employees to perceive change as a phase-shifting event. Considering phase shifting leads to a finer-grained understanding of changes in employees' justice perceptions and anticipations and allows researchers to propose more nuanced recommendations about communication in change programs. Our theoretical model is displayed in Figure 1.

\section{THEORY AND HYPOTHESES}

\section{Fairness Heuristic Theory}

According to FHT (Lind, 2001; Van den Bos et al., 2001), individuals face a fundamental social dilemma when interacting with authorities. Cooperation with an authority can be associated with positive outcomes, but cooperation can also lead to exploitation. FHT suggests that individuals form, and subsequently use, overall justice perceptions as a heuristic to determine whether authorities can be 
FIGURE 1

Antecedents of Phase-Shifting Perceptions and Consequences on Justice Judgments

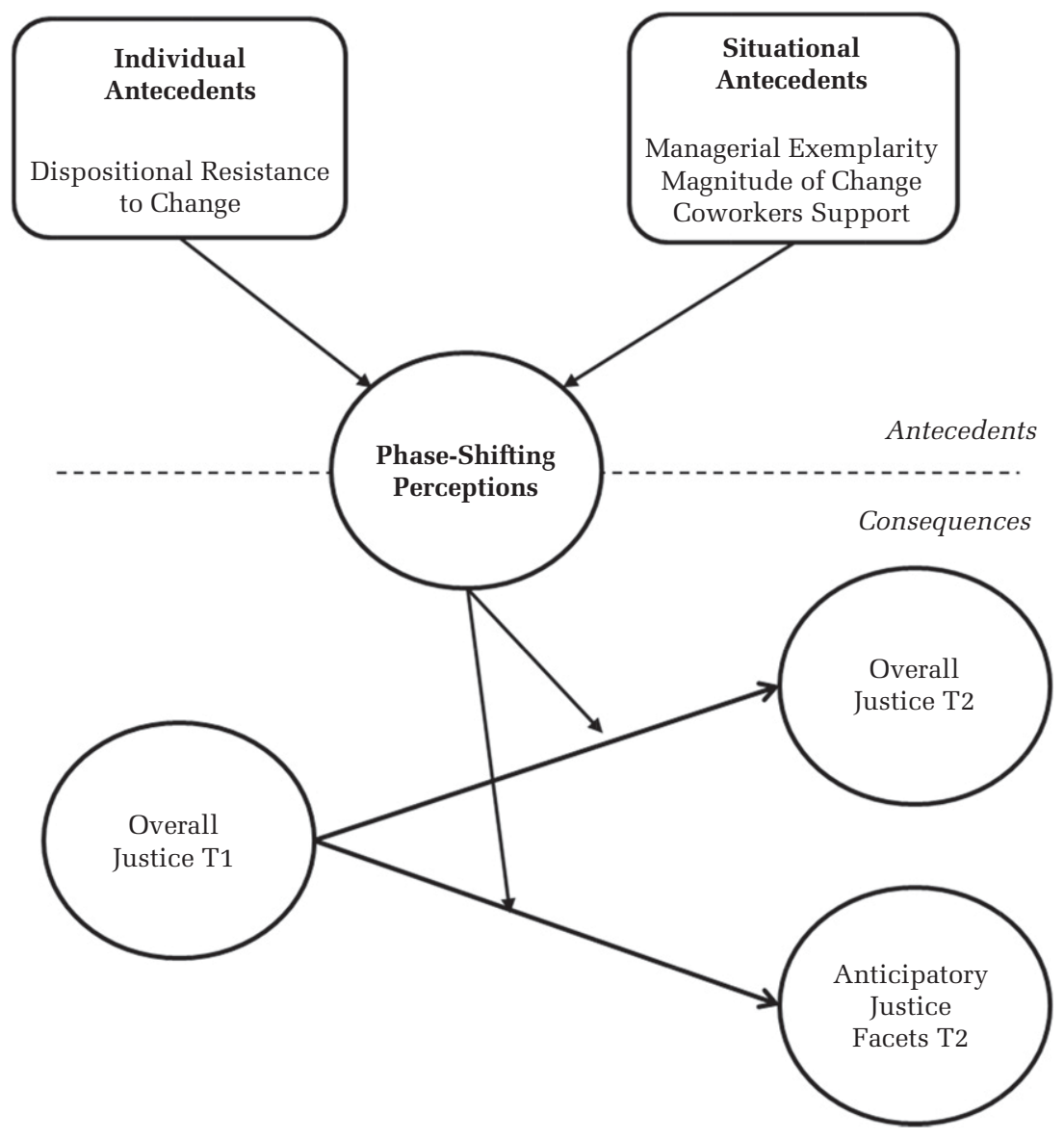

trusted and cooperation is warranted. Central to FHT is the assertion that the generation of justice judgments is episodic, and these judgments are used more frequently than they are revised (Lind, 2001; Van den Bos \& Lind, 2002). The heuristic value of overall fairness judgments is lost if individuals must revise and update fairness evaluations constantly. Thus, Lind (2001) suggested that overall fairness judgments form relatively quickly, and these judgments are maintained unless events indicate a judgment must be updated.

Lind (2001) distinguished two phases during the fairness evaluation process: judgment and use. During the judgment phase-which is typically at the beginning of a new relationship-individuals use available information regarding procedures, distributions, and interactions with authorities to generate a new overall justice judgment. In the use phase, an existing overall justice judgment is used as a heuristic that shapes cognitions and determines appropriate behaviors; incoming information is assimilated to conform to these initial justice judgments and the existing general justice judgment is used to generate facet-specific (procedural, distributive, interpersonal, informational) justice judgments.

According to FHT, certain events may lead individuals to reenter the judgment phase. In these situations, employees reconsider their previous general justice judgments and generate new ones, incorporating available justice-related information (Lind, 2001). This judgment phase produces a new overall justice judgment (Lind, 2001). Lind (2001) labeled events that lead employees to reconsider relationships with their organizations, and thus influence justice judgments, as phase-shifting events. Radical organizational changes, such as M\&As, are examples of phase-shifting events (Lind, 2001).

Lind's distinction between the use phase and the judgment phase matches the distinction between 
two types of processing posited by dual-process theories of cognition-type 1 (intuitive) and type 2 (analytic) $^{1}$ (Evans, 2006; Evans \& Stanovich, 2013). More specifically, Lind's conceptualization is aligned with default-interventionist dual-process theories that suggest most thoughts and actions occur intuitively (type 1, or, in FHT terms, use phase)-i.e., in an effortless and spontaneous way thanks to the use of shortcuts or heuristics (for a general review, see Kahneman, 2003; Strack \& Deutsch, 2004), unless good reasons challenge the ongoing heuristic and constrain the individual to go back to more analytical cognitive processes (type 2, or, in FHT terms, judgment phase) (Evans, 2006; Kahneman, 2003). Consistent with prior research (Cropanzano \& Rupp, 2003), we conceptualize FHT as a specific type of dual-process theory focusing on justice judgments.

\section{Phase Shifting}

The moderating role of phase-shifting perceptions. Although Lind (2001) introduced overall fairness as a construct more than a decade ago, and other researchers raised the issue even earlier (Leventhal, 1980; Lind \& Tyler, 1988), direct empirical research has appeared only recently, and remains limited (see Ambrose, Wo, \& Griffin, 2015, for a review). Overall justice perceptions reflect global evaluations of the fairness of an entity or an event and are the results of both personal experience and knowledge of the experiences of others (Ambrose \& Schminke, 2009; Holtz \& Harold, 2009). Empirical research has demonstrated that overall justice and justice facets are distinct constructs (Ambrose \& Schminke, 2009; Jones \& Martens, 2009; Kim \& Leung, 2007; Nicklin, McNall, Cerasoli, Strahan, \& Cavanaugh, 2014). Our first hypothesis addresses the relationship between perceptions of phase shifting and employees' perceptions of overall justice.

We begin by considering the relationship between overall justice and subsequent judgments when employees remain in the use phase in a context of change (i.e., they do not perceive the change as a phase-shifting event). In the use phase, once the overall justice judgment has been generated,

\footnotetext{
${ }^{1}$ Many terms have been proposed to describe these two types of processes, and the terms often differ across variants of dual-process theories. In this paper, we use Evans and Stanovich's (2013) terminology-i.e., type 1 processes (intuitive) and type 2 processes (analytic).
}

selective attention and cognitive resistance to challenge an ongoing heuristic (Evans, 2006; Strack \& Deutsch, 2004) lead employees to interpret new information as consistent with previous judgments (Lind, 2001; Van den Bos, Vermunt, \& Wilke, 1997). Thus, when employees do not perceive change as phase shifting, overall justice judgments at the beginning of the change (time 1) relate strongly with subsequent (time 2) overall justice judgments.

The situation is different if employees perceive the change as phase shifting. In this case, employees must update their previous justice judgments. Lind (2001) suggested that this process occurs relatively quickly; a new overall justice judgment replaces a previous general evaluation. Lind was not explicit concerning the relationship between the former and latter overall justice judgments; however, it is likely-even in a phase-shift context-that some attributes on which the original judgment was based remain the same, while others change. Thus, when change is perceived as a phase-shifting event, time 1 overall justice judgments relate to time 2 overall justice judgments, but this relationship is weaker than when individuals do not perceive a phase shift. Therefore, we posit the following hypothesis:

Hypothesis 1. The relationship between time 1 and time 2 overall justice is moderated by phaseshifting perceptions, such that the relationship is weaker when employees perceive change as a phase-shifting event.

Phase-shifting perceptions and anticipatory justice. Shapiro and Kirkman $(1999,2001)$ introduced the construct of anticipatory justice, suggesting that when individuals face uncertainty-specifically, organizational change-they form expectations regarding whether they will be treated fairly during the change; they anticipate fairness or unfairness. Anticipatory justice is particularly relevant in an M\&A setting. Like experienced justice (i.e., perceptions of fairness based on experience), anticipatory justice has been conceptualized along four dimensions. Anticipatory distributive justice refers to anticipated fairness of decision outcomes. Anticipatory procedural justice refers to anticipated fairness of the process by which decisions are made. Anticipatory interpersonal justice refers to anticipations regarding concern and respect a supervisor displays when communicating decisions to employees. Anticipatory informational justice refers to anticipated accuracy and honesty of information a supervisor provides when implementing procedures. 
According to FHT, established overall justice judgments influence justice facet judgments. Specifically, Lind (2001) suggested that in the use phase, individuals will rely on their general fairness judgments to guide justice facet judgments. However, in the judgment phase, specific justice experiences will provide the foundation for facet judgments. Thus, when radical organizational change leads employees to reconsider their relationship with the organization, this should also influence justice facet judgments (Lind, 2001; Tost \& Lind, 2010). Specifically, we expect phase-shifting perceptions to moderate the relationship between initial overall justice judgments and later anticipatory justice facet judgments. When change is not perceived as a phase-shifting event, time 1 overall justice judgments should predict time 2 anticipatory justice facets. However, when the change is perceived as a phase-shifting event, anticipatory justice should be based on specific change-related justice experiences, rather than the initial overall justice judgment. Therefore, we suggest:

Hypothesis 2. The relationship between time 1 overall justice judgments and time 2 anticipatory justice facets judgments is moderated by phase-shifting perceptions, such that time 1 overall justice is related to time 2 anticipatory justice facets when employees do not perceive change as a phase-shifting event, but not when the change is perceived as phase shifting.

\section{Antecedents of Phase-Shifting Perceptions}

The second focus of our paper is the antecedents of phase-shifting perceptions. There is a dearth of empirical research on the determinants that lead employees to shift from the use phase to the judgment phase (Jones \& Skarlicki, 2013). To extend FHT (Lind, 2001), we build on dual-process theories (Evans, 2006; Strack \& Deutsch, 2004) to derive hypotheses regarding antecedents of phase shifting.

The core proposition in FHT is that fairness judgments serve as a heuristic that individuals use to process information from the environment and make decisions (Lind, 2001). In the years since the introduction of FHT (Lind, 2001; Van den Bos et al., 2001), advances have been made in our understanding of cognitive processes (Evans, 2006; Strack $\&$ Deutsch, 2004). These advances provide some insights about factors that may influence individuals' perceptions of events as phase shifting. Utilizing the dual-process theory approach provides a framework for examining factors that motivate the reshaping of heuristics (i.e., phase shifting, in Lind's terms). According to dual-process theories, good reasons to abandon heuristics may be rooted in the event, the situation, or individual cognitive characteristics (Strack \& Deutsch, 2004). We utilize these categories of antecedents from the dual-process literature (Evans, 2006; Kahneman, 2003; Strack \& Deutsch, 2004) to identify change-related characteristics that influence phase shifting.

Event-based antecedents. Dual-process theories posit that the analytic process requires centralworking-memory resources (Evans, 1984); hence, individuals shift from automatic to analytic processes only when stakes are sufficiently high to motivate cognitive effort (Fazio, 1987; Kahneman, Slovic, \& Tversky, 1982). Strack and Deutsch (2004) agreed, arguing that stimulus intensity plays a major role in activation of the analytic process. In the context of organizational transformation, the intensity of the stimulus is proportional to the magnitude of the change in employees' situation (Fedor, Caldwell, \& Herold, 2006), such as an increase in work demands and potential role conflicts (Spector, 2002), loss of control regarding the future, and fear of failure (Coch \& French, 1948), as well as additional sensemaking activities (see Maitlis \& Sonenshein, 2010, for a review). Therefore, the greater the magnitude of the transformations generated by the change, the greater the intensity of the situation for employees. Thus, we hypothesize:

Hypothesis 3. The greater the perceived magnitude of change, the more likely the change is perceived as a phase-shifting event.

Situational antecedents. According to dualprocess theories, there are also factors rooted in the environment that influence the attention individuals dedicate to the situation. Attention dedicated to the stimulus is another determinant of analytic process activation (Strack \& Deutsch, 2004). The less attention individuals dedicate to assessing a stimulus, the less they engage in an analytic process. We identify two factors that reduce attention dedicated to a change event and that should therefore reduce the likelihood of it being perceived as a phase-shifting event: exemplarity of top management behaviors in relation to the change, and coworkers' support of that change.

Building on Bandura's (1986) argument that environment largely determines attitudes and 
behaviors, several studies have emphasized the role of managers' change behaviors in employees' subsequent change behaviors (Labianca, Gray, \& Brass, 2000; Melkonian, Monin, \& Noorderhaven, 2011). In uncertain environments characterized by lack of information, employees scrutinize the behaviors of authorities (Armeneikis et al., 1995) and gauge the degree to which their proximal managers' change behaviors are consistent with change behaviors they are expected to display (i.e., managerial exemplarity). Recent research has demonstrated that employees' perceptions of managerial exemplarity are associated with employees' cooperation with the change (Melkonian et al., 2011). We suggest that when managers display change behaviors employees are expected to adopt, employees perceive the change requirements as more consistent, and thus dedicate less attention to the change. However, if employees perceive the behaviors of managers as inconsistent with behaviors required of employees, it creates a discrepancy that motivates them to dedicate more attention to the change. Increased scrutiny ushers employees back to the judgment phase by stimulating the analytic process. Thus, we suggest:

Hypothesis 4. The higher the perceptions of managerial exemplarity, the less likely employees are to perceive change as a phase-shifting event.

The role of social support in predicting individuals' reaction to organizational change is well-established (Oreg, 2006). In periods of change, employees strive to make sense of their environment. The social environment "provides cues which individuals use to construct and interpret events. It also provides information about what a person's attitudes and opinions should be" (Salancik \& Pfeffer, 1978: 226). Coworkers play a critical role in the process of interpreting the environment by providing information and supporting some activities while discouraging others. A meta-analysis by Chiaburu and Harrison (2008) demonstrated that coworkers' support influences individuals' work attitudes and perceptions, even when controlling for leaders' influence. When there is a lack of social support for the change in an employee's proximal environment, it suggests that the change warrants attention, which may lead to a shift to the analytic processing (or judgment phase, in FHT terms). Like the absence of managerial exemplarity, lack of social support for change signals that something is wrong or inconsistent, and that more attention should be dedicated to assessment of the change. This additional attention stimulates the analytic process associated with phase shifting. Therefore:

Hypothesis 5. The higher employees' perceptions of social support for change, the less likely they are to perceive change as a phase-shifting event.

Individual antecedents. Dual-process theories also identify individual characteristics that influence the shift from heuristic to analytic processing. Some people might process an event through heuristic methods, but the same event might trigger analytic cognitive processes among others (i.e., may lead them to a phase shift). Evans (2006) identified cognitive resistance-that is, a dispositional lack of flexibility or willingness to consider alternativesas a factor that explains maintenance of ongoing heuristics (type 1 intuitive cognitive processes, or in FHT terms, use phase). Individuals with low cognitive rigidity revisit justice heuristics more easily. That is, they are more prone to phase shifting. In the context of organizational change, cognitive rigidity is reflected in Oreg's (2003) concept of DRTC. Studies (Oreg, 2003; Oreg et al., 2008) examining DRTC have demonstrated that it predicts individuals' reactions to change in a variety of contexts under both voluntary and imposed conditions. Individuals with a high dispositional resistance to change tend to be attached to the status quo and unwilling to consider alternative ideas and perspectives. They are also less likely to revise their cognitive schemata, which include fairness heuristics. Therefore, we hypothesize that:

Hypothesis 6. The higher employees' dispositional resistance to change, the less likely they are to perceive change as a phase-shifting event.

\section{METHOD}

\section{Data Collection}

This study was conducted in two companies, one in France and one in Spain, undergoing a merger. Time 1 data were collected just after the initial announcement of the merger, and time 2 data were collected six months later, while the merger was being implemented. The merger was scheduled to be completed in 12 months. A large international manufacturer of consumer goods acquired both companies five years prior to the study to better control distribution of products in Europe. Operating 
as exclusive dealers, both subsidiaries remained autonomous for five years, each with their own independent executive committee, a large proportion of unique products adapted to local markets' needs, and independent sales and marketing operations. The controlling firm acted as a financial holding company. To reduce operating costs and develop an integrated distribution strategy throughout Europe, the company merged the French and Spanish divisions. A joint executive committee was created, and a plan was developed to integrate the two entities. In addition to joining the two companies' operations, the plan included an overhaul of the business model. Instead of focusing solely on the primary company's products, the new entity would distribute non-direct-competing products and act as a standalone wholesaler. This was how both companies operated prior to the initial acquisition.

Employees were notified about participation in the study through direct communication from managers and union representatives. The first survey was conducted a few days after the announcement of the merger. Since changes would occur over the coming months, the survey focused on the announcement phase. Participants were asked about their views of the overall fairness of the organization and past organizational fairness. They were also asked about their views of change in general (i.e., dispositional resistance to change and experiences with change). General biographic data (i.e., age, gender, organizational tenure) were also collected. A second survey was conducted six months later. Although the merger was taking place at that point, it was a work in progress, and ongoing changes were anticipated for another six months. Some of the most important structural changes had yet to be implemented. Participants were asked about their expectations regarding specific facets of fairness for change outcomes and processes. They were also asked about their perceptions of the magnitude of the change, whether colleagues supported the change, and about top manager exemplarity with regard to the change. For both surveys, participants were provided with return mailing envelopes, to ensure that all surveys would be returned directly to the researchers and not to the company. The covering letter accompanying the surveys indicated that the study was being conducted for academic purposes and that only general statistics would be communicated to managers and unions to ensure anonymity. The data used in this article were collected as part of a broader data collection effort. Time 1 data were used to explore the moderating role of informational distance on the relative determinants of cooperation (see Melkonian, Soenen, \& Ambrose, 2015). The only variable overlapping the two studies is time 1 overall justice, which is used here as an independent variable, while it is used as a control variable in the other study.

\section{Sample}

A total of 234 participants completed the premerger survey, providing a response rate of $34 \%$. In the Spanish company, the response rate was $37 \%$; in the French, $30.5 \%$. Six months later, we mailed the second survey to all employees, regardless of whether they had participated in the first survey. A total of 228 participants completed the implementation survey, giving a response rate of $34 \%$. The response rate dropped to $30 \%$ in the Spanish company, and for the French company it rose to $45 \%$. Of the 234 employees who answered the first survey, 18 were no longer employed by the company at the time of the second survey. A total of 115 employees responded to both surveys, equating to $53.2 \%$ of time 1 respondents. Participants worked in all departments of both companies, including sales, IT, marketing, and supply chain. On average, participants were 40.6 years old ( $S D=8.4$ years), with average tenure of 11.5 years $(S D=8.9$ years). A total of $18 \%$ were women, and $46 \%$ were French and $54 \%$ Spanish.

\section{Measures}

For all measures, items were translated from original English scales into French and Spanish, and then back-translated into English to control translation quality. Two independent translators fluent in English and French or English and Spanish assessed discrepancies. The measures can be found in Appendix A.

Perceived phase shifting. Given our objective to test phase shifting as per FHT conceptualization, we operationalized the concept using the two components originally proposed by Lind (2001). Thus, to assess perceived phase shifting, we created two questions, one for each determinant of phase shifting as defined by Lind (2001: 78). The first aspect (i.e., signs that the relationship with the organization is changing) was measured with "This change makes me reconsider my relationship with the 
organization." The second aspect (i.e., fairness of relevant information that falls outside expectations) was measured with: "The fairness of activities related to the change is very different from what I have come to expect from this company." Participants rated their agreement with these statements using a seven-point scale, with anchors strongly disagree (1), neither agree nor disagree (4), and strongly agree (7). Perceived phase shifting was measured at time 2.

Conceptually, Lind's (2001) description of phaseshifting perceptions reflects a dichotomy, as the perceived event either does or does not cause the perceiver to shift from the use phase to the judgment phase. This conceptualization is consistent with dual-process theories. Dual-process theories (Evans, 2008, 2010; Stanovich, 1999, 2011) conceive of the two types of processing as being discrete and not as forming a continuum. Thus, we dichotomized the perceived phase-shifting variable. ${ }^{2}$ We grouped respondents into the phase-shift and no phase-shift categories in the following way: first, for each of the two questions relating to perceptions of phase shifting, answers 1 (strongly disagree) through 4 (neither agree nor disagree) were categorized as No Perceived Phase Shifting (0) and answers 5 to 7 (strongly agree) were categorized as Perceived Phase Shifting (1). We included 4 in the "No Perceived Phase Shifting" category because individuals experiencing a phase shift are conscious of it and would not give a neutral answer. We then created a binary phase-shifting variable from the answers to the two questions. Because the two questions reflect independent conditions for there to be a perception of phase shift, it requires only one of the two modalities (i.e., perceptions that the relationship with the organization is changing or perceptions of fairness of relevant information that falls outside expectations) for someone to be experiencing change as a phase-shifting event. Thus, if respondents were categorized as perceiving a phase shift on either of the two questions, they received a 1 on the perceived phase-shifting measure. It they were categorized as not perceiving a phase shift on both questions, they were coded 0 on the phaseshifting measure. This coding resulted in $58 \%$ of

\footnotetext{
${ }^{2}$ There is an empirical basis for dichotomizing the phase-shifting measure as well. An examination of the responses reveals a bimodal distribution, which is the single most important justification for dichotomizing (DeCoster, Iselin, \& Gallucci, 2009).
}

respondents experiencing the merger as a phaseshifting event, while $42 \%$ did not. ${ }^{3}$

Overall justice. We assessed overall justice with the three-item short version of Ambrose and Schminke's (2009) perceived overall justice scale. This scale uses the three personally focused scale items. Ambrose and Schminke (2009) reported that the shortened scale has acceptable reliability and performs equally well compared to the six-item scale. At both time 1 and time 2, participants rated their degree of agreement using a seven-point scale ranging from "to a very small extent" to "to a great extent." A sample item included "In general, I can count on this organization to be fair."

Anticipatory justice facets. We measured anticipatory distributive, procedural, and interactional justices at time 2 with items adapted from Rodell and Colquitt (2009) to match the context of the study. Participants were provided with a five-point scale ranging from "to a very small extent" to "to a great extent" to assess the degree to which they agreed with statements in each scale. We referenced justice items to implementation of the change (i.e., the merger and the new business model).

To assess anticipatory procedural justice, participants were told to refer to "the procedures you anticipate will be used to implement this change." To assess anticipatory distributive justice, participants were asked to "refer to the outcomes (e.g., pay, bonuses, promotions, opportunities for training, etc.) you anticipate receiving personally as consequences of this change." To assess anticipatory interpersonal

\footnotetext{
${ }^{3}$ To assess the efficacy of a dichotomized measure of phase shifting, we conducted a scenario-based experiment in which we manipulated phase shifting and measured perceived phase shifting with a yes-no version of the phase-shifting measure used in this study. As in the field study, we recoded the two dichotomized indicators of phase shifting (change in relationship-yes-no and fairness very different from what is expected-yes-no) into a single dichotomized measure such that an affirmative answer to either question was coded as a perceived phase shift and a negative answer to both questions was coded as no perceived phase shift. The dichotomized measure of phase shifting significantly predicted cognitive processing types. As is typically shown in dual-process experimental studies (De Neys, 2006), individuals who perceived the event described in the scenario as phase shifting took longer to respond than did individuals who did not perceive the event as phase shifting $(t=-2.26, p<.05)$. This experiment also replicated the change in overall justice judgments that was found in the field study. Details about the experiment can be obtained from the first author.
} 
justice, participants were asked to "refer to how you anticipate your supervisor will treat you during this change." For informational justice, they were asked to "refer to the communication about the change."

Magnitude of change. We created the following item to assess magnitude of change: "Compared to how you were working before, this change is...?" Participants used a four-point scale, with anchors "not really a change (1)," "a minor change (2)," "an important change (3)," and "a fundamental change (4)." This was measured at time 2.

Managerial exemplarity. We used an item from Melkonian et al. (2011) to assess employees' perception of exemplarity: "So far, my manager has behaved in accordance to what is expected from the rest of the employees, notably in terms of cooperation behaviors." Participants rated degree of agreement on a seven-point scale ranging from "to a very small extent" to "to a great extent," measured at time 2.

Social support. We measured social support at time 2 with one item from Oreg (2006): "Do your colleagues support the change?" Participants rated their degree of agreement on a five-point scale of "yes, clearly (1)," “overall, yes (2)," “yes, somewhat (3)," "not really (4)," and "definitely not (5)" (responses were reverse coded in the analyses).

Dispositional resistance to change. DRTC was measured at time 1 with Oreg's (2003) 17-item scale. A sample item included "I don't change my mind easily," Participants rated their degree of agreement on a six-point scale, anchored with "strongly disagree" to "strongly agree."

Control variables. To test Hypotheses 3 through 6 (antecedents of phase shifting), we controlled for a number of variables. We controlled for tenure (measured in years at time 1), as perceptions of phase shifting might be affected by length of employee relationships with an organization. Newly recruited employees lack a strong historical reference to compare the change to, which may make it difficult for them to assess whether the current change is a phase-shifting event. We also controlled for entity, as the change was an international M\&A, and unbalanced power dynamics among merging entities might have influenced perceptions of change (measured at time 1). There were two entities impacted by the merger, one in France and one in Spain. We also controlled for change favorableness since cognitive appraisals of change are influenced by outcome favorability (Fedor et al., 2006). Change favorableness was measured at time 2 with the item: "On a personal level, is this change a good thing for you?"
Respondents used the following scale: "yes, clearly (1)," "overall, yes (2)," "yes, somewhat (3)," "not really (4)," and "definitely not (5)" (responses were reverse coded in the analyses). Additionally, we controlled for past organizational fairness in terms of change management, measured at time 1 ("In the past, has this organization managed organizational change in a fair manner?"). Respondents used the following scale: "yes, clearly (1)," "overall, yes (2)," "yes, somewhat (3)," "not really (4)," and "definitely not (5)" (responses were reverse coded in the analyses). This is an important context-related control because an employee's past justice perceptions may influence how he or she will perceive and anticipate the fairness of the upcoming changes (Rodell \& Colquitt, 2009; Shapiro \& Kirkman, 1999). We also added a more general control with change experiences since this could also influence an individual's interpretations of a new change, irrespective of the specific change in question. Experience with change was assessed at time 1 with the item: "How would you describe your previous experience(s) with organizational changes?" Respondents used a fivepoint scale from "very negative" to "very positive."

\section{RESULTS}

The results are presented in two sections. First, we report our results pertaining to the moderating effect of phase-shifting perceptions (Hypothesis 1 and Hypothesis 2); then, we report results pertaining to its antecedents (Hypotheses 3 through 6).

\section{Consequences of Phase-shifting Perceptions}

Preliminary analyses. Correlations, means, standard deviations, and reliabilities are shown in Table 1. To assess the psychometric properties of the measures, we conducted a series of confirmatory factor analyses (CFAs) on the justice items (see Table 2). For the anticipatory justice items, we conducted a CFA to assess the fit of the theorized sixfactor model (time 1 overall justice, time 2 overall justice, and time 2 anticipatory distributive, procedural, informational, and interactional justice). The results indicated that the six-factor model provided a good fit to the data: the CFI was .96 and IFI .96 (Bentler, 1990), and a RMSEA value of .06 was acceptable (Browne \& Cudeck, 1993). We compared this model with three alternative models: a threefactor model (all of the anticipatory justice items in one factor and the overall justice items in a second and third factor), and a two-factor model (justice 
TABLE 1

Consequences of Phase-shifting Perceptions: Means, Standard Deviations, and Correlations

\begin{tabular}{|c|c|c|c|c|c|c|c|c|c|}
\hline Variable & $M$ & $S D$ & 1 & 2 & 3 & 4 & $\mathbf{5}$ & 6 & 7 \\
\hline 1. Phase-Shifting Perceptions (T2) & 0.58 & 0.49 & NA & & & & & & \\
\hline 2. Overall Justice (T1) & 4.31 & 1.25 & -0.06 & $(0.81)$ & & & & & \\
\hline 4. Anticipatory Distributive Justice (T2) & 2.81 & 0.99 & -0.03 & $0.21 * *$ & $0.52 * *$ & $(0.94)$ & & & \\
\hline 5. Anticipatory Procedural Justice (T2) & 3.05 & 0.77 & $-0.22^{*}$ & $0.43^{* *}$ & $0.51^{* *}$ & $0.52 * *$ & $(0.85)$ & & \\
\hline 6. Anticipatory Informational Justice (T2) & 4.27 & 0.81 & -0.12 & $0.33^{* *}$ & $0.43^{* *}$ & 0.11 & $0.46 * *$ & $(0.92)$ & \\
\hline
\end{tabular}

Notes: $n=115$. All statistical tests are two-tailed. Reliabilities (coefficient $\alpha$ ) shown in parentheses when applicable.

${ }^{*} p \leq .05$

${ }^{* *} p \leq .01$

items at time 1 in the first factor and all the justice items at time 2 in one global justice factor). We also compared the fit to a five-factor model, combining anticipatory informational justice and anticipatory interactional justice. None of the alternative models provided an adequate fit to the data. Hence, the sixfactor model was a significantly better fit than the three alternatives (see Table 2.)

Hypothesis testing. To test Hypotheses 1 and 2, we used the multi-group procedure proposed by Rigdon, Schumaker, and Wothke (1998). We chose the multigroup approach over other alternatives for two reasons. First, the choice is related to the dichotomous nature of the moderating variable. Second, the multigroup procedure allowed us to test the moderation hypothesis across all our dependent variables simultaneously. Given the size of our sample, we ran the multi-group analysis using a partially latent model, in which scale scores were used as single indicators of the latent variable with factor loadings set to ([1 - scale reliability $]^{*}$ scale variance) (Kline, 2005; Rodell \& Colquitt, 2009). Kline (2005) suggested that statistical precision will be adequate when the ratio of sample size to observed variables exceeds 5 to 1 , and a partially latent approach allowed our ratio to be 11.5 to 1 . As is fairly common practice in structural equation modeling (e.g., Judge \& Colquitt, 2004; Rodell \& Colquitt, 2009), the disturbance terms for some endogenous justice variables are allowed to covary to capture all unmeasured common causes. The model provided a good fit to the data, $\chi^{2} / d f=107.43 / 54=$ 1.98, CFI $=.93$; IFI $=.93$; $\mathrm{RMSEA}=.08$. To assess the statistical significance of differences in regression weights between groups, we estimated critical ratios for differences simultaneously for all paths in the model. Results of the comparative path-analyses between groups, shown in Table 3 and displayed in Figure 2, revealed that, consistent with our hypotheses, phase-shifting perceptions

TABLE 2

Measurement and Structural Model Results

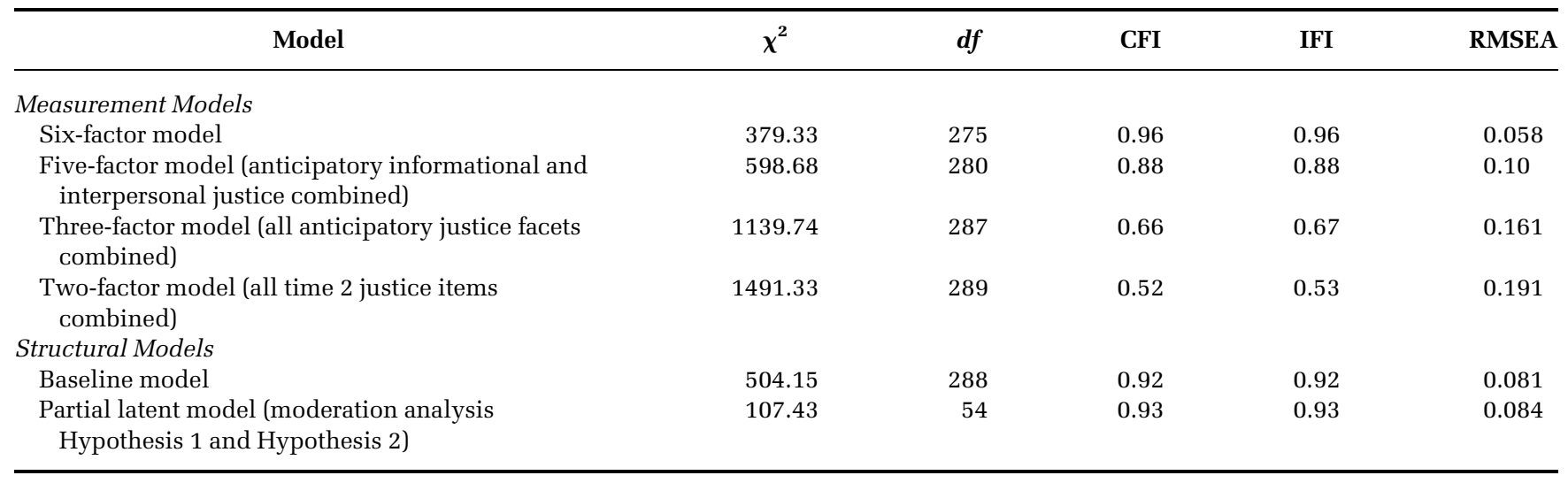

Notes: $\mathrm{CFI}=$ comparative fit index; IFI = incremental fit index; RMSEA = root mean square error of approximation. 
TABLE 3

Consequences of Phase Shifting: Comparative Path Analysis

\begin{tabular}{|c|c|c|c|c|c|}
\hline & & & No Perceived Phase Shifting & Perceived Phase Shifting & \\
\hline \multirow[t]{4}{*}{ OJ T1 } & $\rightarrow$ & Overall justice T2 & $0.86^{* * *}$ & $0.43^{* *}$ & $-2.18 * *$ \\
\hline & $\rightarrow$ & Anticipatory procedural justice T2 & $1.38^{*}$ & 0.50 (n.s.) & $-1.93^{*}$ \\
\hline & $\rightarrow$ & Anticipatory informational justice T2 & $1.77 * *$ & 0.20 (n.s.) & $-2.32^{* *}$ \\
\hline & $\rightarrow$ & Anticipatory interpersonal justice T2 & $1.68^{*}$ & 0.25 (n.s.) & $-2.02 * *$ \\
\hline
\end{tabular}

Notes: $n=115$. All statistical tests are two-tailed

${ }^{a} Z$-score tests for differences in $\beta$ coefficients across the two conditions of phase shifting.

${ }^{*} p \leq .05$

$* * p \leq .01$

$* * * p \leq .001$

moderated the relationship between initial and later overall justice judgments, as well as the relationship between initial justice judgments and all anticipatory justice facets except for anticipatory distributive justice.

Antecedents of phase-shifting perceptions. Our second set of analyses examined Hypotheses 3-6 and focused on antecedents of phase shifting.
Correlations, means, standard deviations, and reliabilities for the antecedents of phase-shifting perceptions are shown in Table 4.

To examine the hypotheses regarding antecedents of phase-shifting perceptions, we conducted a binary logistic regression. The technique is useful when modeling the event probability for a categorical response variable with two outcomes-in this

FIGURE 2

The Moderating Role of Phase-Shifting Perceptions on Justice Judgments—Results

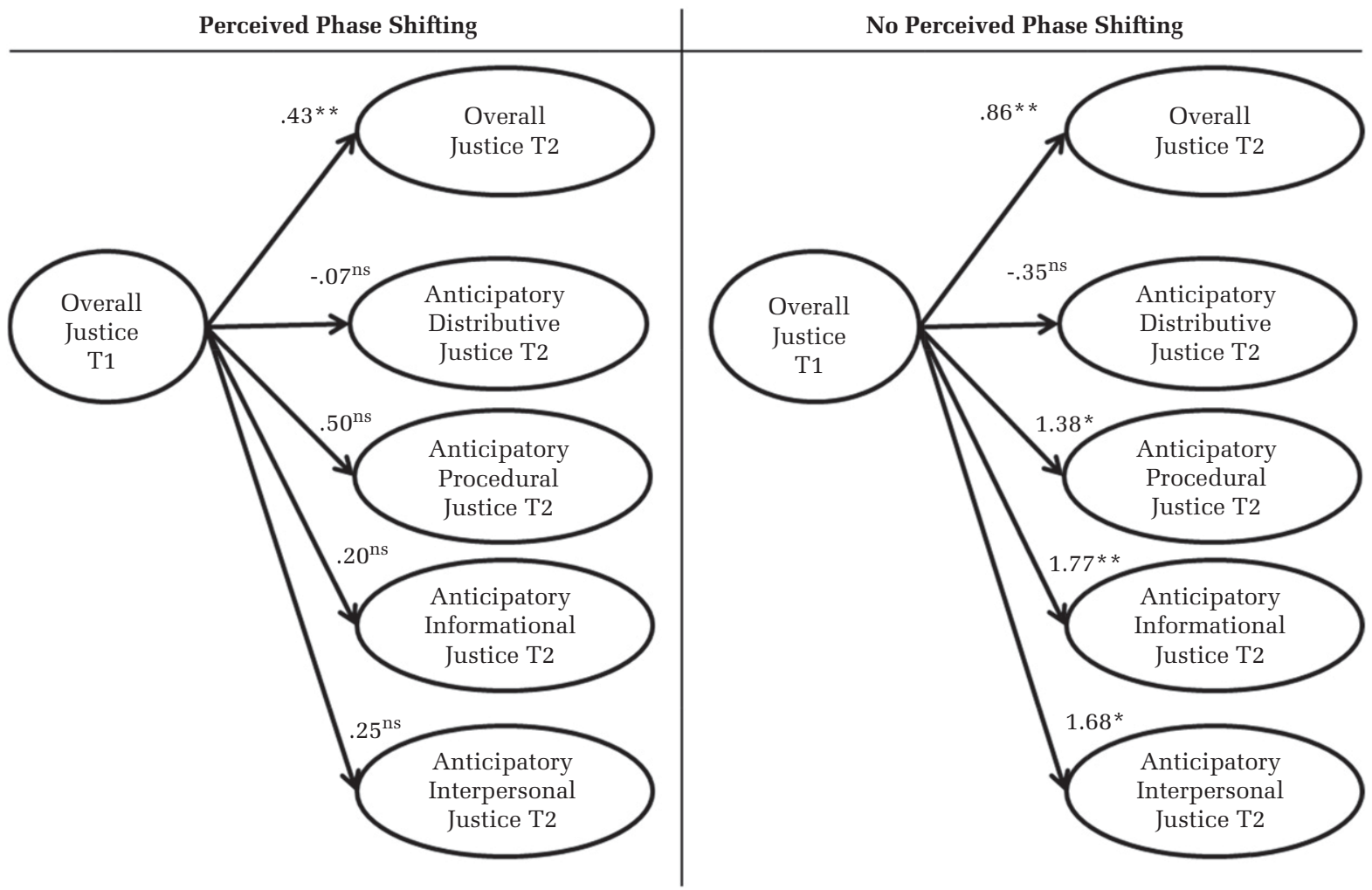


TABLE 4

Antecedents of Phase-Shifting Perceptions: Means, Standard Deviations, and Correlations

\begin{tabular}{|c|c|c|c|c|c|c|c|c|c|c|c|}
\hline Variable & $M$ & $S D$ & 1 & 2 & 3 & 4 & 5 & 6 & 7 & 8 & 9 \\
\hline 1. Phase shifting (T2) & 0.58 & 0.49 & NA & & & & & & & & \\
\hline 2. Tenure (T1) & 1.54 & 0.50 & 0.10 & NA & & & & & & & \\
\hline $\begin{array}{l}\text { 4. Previous experience with } \\
\text { change (T1) }\end{array}$ & 2.62 & 0.84 & -0.03 & -0.04 & 0.15 & NA & & & & & \\
\hline $\begin{array}{l}\text { 5. Past organizational fairness } \\
\text { (T1) }\end{array}$ & 3.08 & 0.94 & 0.13 & 0.09 & -0.07 & 0.17 & NA & & & & \\
\hline 7. Change magnitude (T2) & 2.45 & 0.88 & $0.30 * *$ & -0.05 & -0.14 & -0.14 & 0.01 & $0.19^{*}$ & NA & & \\
\hline 8. Managerial exemplarity (T2) & 3.95 & 0.97 & -0.14 & -0.01 & -0.01 & -0.10 & -0.18 & $0.30^{* *}$ & $0.23^{*}$ & NA & \\
\hline $\begin{array}{l}\text { 9. Dispositional resistance to } \\
\text { change (T1) }\end{array}$ & 3.12 & 0.97 & $-0.25^{* *}$ & -0.10 & -0.04 & -0.12 & -0.11 & $0.40^{* *}$ & 0.05 & $0.25^{* *}$ & $(0.82)$ \\
\hline $\begin{array}{l}\text { 10. Social support for change } \\
\text { (T2) }\end{array}$ & 2.76 & 0.60 & $-0.20^{*}$ & -0.11 & $0.22^{*}$ & $0.27^{* *}$ & -0.07 & -0.14 & -0.14 & 0.11 & -0.06 \\
\hline
\end{tabular}

Notes: $n=115$. All statistical tests are two-tailed. Reliabilities (coefficient $\alpha$ ) shown in parentheses when applicable.

${ }^{*} p \leq .05$

${ }^{* *} p \leq .01$

study, No Perceived Phase Shift versus Perceived Phase Shift. We tested four main effects: change magnitude, managerial exemplarity, social support for change, and dispositional resistance to change. The results are shown in Table 5 . Consistent with predictions, magnitude of change $(p<.01)$, dispositional resistance to change $(p<.05)$, and social support $(p<.01)$ were significant. Managerial exemplarity did not meet traditional standards of significance $(p<.10)$. No control variable was significantly related to phase-shifting perceptions (except for tenure, which had a value of .01, producing an increase in the probability of perceptions of phase shifting). The results supported Hypotheses $3-6{ }^{4}$

In terms of effect size, the probability of perceiving a change as a phase-shifting event was strongly influenced (in decreasing magnitude) positively by magnitude of change and negatively by social support, DRTC, and managerial exemplarity. The final model classified $60.4 \%$ of those who did not perceive the change as a phase-shifting event, and $83.6 \%$ of those who did, yielding an overall classification of $74 \%$. The model was better at predicting entry into a judgment phase (perceived phase shifting) in comparison to remaining in a use phase (no perceived phase shifting).

\footnotetext{
${ }^{4}$ We also conducted these analyses without controls. The pattern of results remained the same.
}

\section{DISCUSSION}

FHT has been widely used in the justice literature. Yet, to date, no research has explicitly examined individuals' perceptions of an event as phase shifting and the consequences and antecedents of these perceptions. We provide an empirical test of this core tenet of FHT. The results demonstrate that phaseshifting perceptions moderate the relationship between initial overall justice and both subsequent overall justice judgments and anticipatory justice facets. Additionally, our results demonstrate that both individual and situational factors are associated with phase shifting. Combined, these findings contribute to a greater understanding of how and when individuals modify their justice judgments.

Although mergers are often used as an example of a phase-shifting event (Lind \& Van den Bos, 2002), our results demonstrate that while some employees may perceive this organizational change as a phaseshifting event, others may not. Additionally, consistent with dual-process theories (Evans, 2006; Strack \& Deutsch, 2004) and as predicted by FHT (Lind, 2001), the results demonstrate that when employees perceive organizational change as a phaseshifting event, initial overall justice judgments have less influence on subsequent overall justice judgments. In contrast, for employees remaining in the use phase (who do not perceive the change as phase shifting), this is not the case.

Our results also demonstrate that the moderating role of phase shifting extends to the relationship 
TABLE 5

Logistic Regression Model: Antecedents of Phase-Shifting Perceptions

\begin{tabular}{|c|c|c|c|c|c|c|}
\hline Model predictors $^{\mathbf{a}}$ & $\boldsymbol{b}$ & $S E$ & Wald's $\chi^{2}$ & $d f$ & $p$ & Odds ratio $^{b}$ \\
\hline Constant & 0.43 & 0.23 & 3.64 & 1 & 0.06 & 1.54 \\
\hline \multicolumn{7}{|l|}{ Controls } \\
\hline Tenure (T1) & 0.62 & 0.25 & 6.09 & 1 & 0.01 & 1.86 \\
\hline Entity (T1) & 0.25 & 0.25 & 1.15 & 1 & 0.28 & 1.28 \\
\hline Previous experience with change (T1) & -0.07 & 0.25 & 0.09 & 1 & 0.76 & 0.93 \\
\hline Past organizational fairness (T1) & 0.26 & 0.24 & 1.13 & 1 & 0.29 & 1.29 \\
\hline Change favorableness (T2) & 0.03 & 0.26 & 0.17 & 1 & 0.90 & 1.03 \\
\hline \multicolumn{7}{|l|}{ Antecedents } \\
\hline Change magnitude (T2) & 1.03 & 0.29 & 13.06 & 1 & 0.01 & 2.82 \\
\hline Managerial exemplarity (T2) & -0.41 & 0.25 & 2.6 & 1 & 0.10 & 0.66 \\
\hline Dispositional resistance to change (T1) & -0.47 & 0.25 & 3.7 & 1 & 0.05 & 0.62 \\
\hline Social support for change (T2) & -0.71 & 0.27 & 6.72 & 1 & 0.01 & 0.49 \\
\hline Overall model evaluation & Cox \& Snell $R^{2}$ & Nagelkerke $R^{2}$ & $\chi^{2}$ & $d f$ & $p$ & $-2 L L$ \\
\hline Likelihood ratio tests ratio & 0.27 & 0.36 & 35.82 & 9 & 0.00 & 120.4 \\
\hline
\end{tabular}

${ }^{\text {a }}$ Variables were standardized.

${ }^{\text {b }}$ Odds ratio greater than 1 represents increases in the odds of perceiving a change as a phase-shifting event.

between overall justice and anticipatory justice judgments. Although consistent with our predictions, here the pattern differs slightly from that found with overall justice judgments. Whereas phase shifting weakens the relationship between overall justice at time 1 and overall justice at time 2, phase shifting eliminates this relationship for the anticipatory justice facets. No Phase Shifting employees appear to rely on their initial general justice judgments as a basis for their future expectations of the fairness of the specific change experience. When employees perceived the merger as phase shifting, it appears this general judgment is no longer useful. Rather, employees rely on specific, change-related justice information to form their expectations about the future fairness of the change.

The second focus of our study-antecedents of phase-shifting perceptions-explored determinants that lead employees to reenter a judgment phase. Consistent with dual-process theory, the results demonstrate that factors that reduce the amount of attention employees dedicate to a change (e.g., smaller change magnitude, positive top manager exemplarity, and social support for change) are not associated with a perceived phase-shift. The impact of social influence is particularly notable. If an employee's colleagues support a change, he or she is not prompted to reassess ongoing justice judgments. However, colleagues who have a negative attitude toward change appear to motivate employees to reconsider ongoing judgments by offering cues suggesting that reassessment is necessary. A similar pattern occurred for managerial exemplarity (although this effect was marginally significant). If top managers adopt the behaviors required by the change (and expected from the rest of the organizational members), employees will dedicate less attention to questioning the change. These results support the importance of employees' proximal environment as a source of information (Bandura, 1986; Salancik \& Pfeffer, 1978) and highlight the impact of the behavior of both peers (Chiaburu \& Harrison, 2008) and managers (Kernan \& Hanges, 2002; Labianca et al., 2000) during times of change.

Our results also demonstrate that individuals' dispositions are related to phase-shifting perceptions. Employees' cognitive resistance to change also plays a role in reducing perceptions that a change is a phase-shifting event. The higher an employee's dispositional cognitive resistance to change, the less he or she reconsiders ongoing heuristics and reenters a judgment phase. Paradoxically, although cognitive resistance to change is commonly portrayed as a negative characteristic (Oreg, 2003), it might exert a positive influence in some cases. Whether this influence is deemed positive depends on the nature of existing overall fairness and ongoing heuristics. When existing overall fairness perceptions are positive, our results suggest that a change agent should strive to present the change process as "business as usual," as a continuation of existing (fair) procedures; thus, he or she benefits from high cognitive resistance. However, if past overall justice perceptions are negative, it is in the change agent's best interest to create a context in which employees reassess justice judgments. In this context, the higher 
an employee's cognitive resistance, the more it takes to initiate cognitive reevaluation of fairness heuristics. By showing that individuals' appraisal of a change as a phase-shifting event is a function of both context and individuals' characteristics, our results are in line with the trait-situation interactionist approach recently promoted and demonstrated in justice research (Bobocel, 2013) and highlights the need to consider both when examining fairness in organizations.

Our research provides a number of contributions. Theoretically, we expand FHT by demonstrating the importance of considering phase shifting as a perceptual variable. Additionally, drawing on dualprocess theories, we identify three categories of variables (the event, the situation, and the individual) that should be associated with phase shifting. Further, integrating FHT and dual-process theories opens up new avenues for justice research-and may lead us to question some of our assumptions about fairness. For example, according to FHT, fairness judgments are typically stable (Lind, 2001). Cropanzano and Rupp (2003: 89) stated, "once the initial fairness evaluation is made, it is very difficult to alter this evaluation in that one is typically 'stuck' at the level of the initial fairness judgment." Thus, FHT suggests that phase shifting should be a rare occurrence. However, adopting a dual-process perspective, and defining phase shifting as an individual perception that triggers a shift from type 1 (intuitive) to type 2 (analytic) cognitive processes leading to the reevaluation of justice judgments, may lead to a different conclusion. Indeed, according to dual-process theory (Evans, 2006; Strack \& Deutsch, 2004), type 2 processes are relatively frequent; reconfiguration of fairness judgments may actually be more frequent than previously assumed.

Paying attention to the presence or absence of phase shifting may also help to improve the quality of predictions concerning the relationship between overall justice and outcomes. For instance, Rodell and Colquitt (2009) addressed the extent to which anticipatory justice facets and supervisory overall fairness combine to predict smoking ban reactions. They found that experienced procedural justice is not predicted by overall supervisory fairness. This lack of relationship may be because a majority of individuals experienced the change (smoking ban) as a phase-shifting event and therefore no longer relied on their preexisting overall justice perceptions to determine their attitudes toward the change. Similarly, Bobocel's (2013) findings on the role of overall justice as an antecedent of constructive versus destructive coping with unfair treatment may be interpreted though the lens of perceived phase shifting. Bobocel reported that overall justice combined with self-concern and other-orientation explain an additional $8 \%$ of variance in forgiveness, above and beyond control variables, while no effect was found for overall justice on revenge. One potential explanation for the differential impact of overall fairness may be that individuals who perceive events as phase-shifting have a stronger urge to take revenge, whereas individuals who choose to forgive do not see events as phase shifting. Recognizing the importance of individuals' perceptions of an event as phase shifting (or not) may enhance our understanding of the effect of overall fairness.

Our research also contributes to research on M\&As. A recent review of the literature on organizational change by Oreg, Vakola, and Armenakis (2011) concluded that the role of proximal environment in determining individuals' response to change has mainly been operationalized through measures of managerial support and trust. Our results show that both managerial exemplarity and coworker support are two additional aspects of the proximal environment that, through their impact on perceptions of phase shifting, influence employees' justice judgments and anticipations.

\section{Practical Implications}

In terms of managerial implications, this study demonstrates the importance of context in employees' reactions to organizational change, especially the influence of coworkers' attitude toward the change (Chiaburu \& Harrison, 2008), as well as managers' change behaviors (Labianca et al., 2001). Additionally, the results suggest that in order to create support for change, it might not always be in the best interest of change agents to trigger justice reassessment, as is often recommended (Tost \& Lind, 2010). Conversely, it might not always be in the interest of change agents to present the change as a historical continuity either (Chreim, 2005). Our study suggests that managers should organize their communication strategy in order to present the merger as distinct from the past under two conditions: first, prechange overall justice judgments are negative, and second, the organization is able to ensure sufficient fairness during the change process. On the contrary, when there is a favorable historic justice climate and potentially unfair change consequences, it might be in the change agent's best interest to present the change as an historical 
continuity. These recommendations are consistent with the change management literature, which has highlighted a need to consider organizational history (Pettigrew, Woodman, \& Cameron, 2001) and the importance of preliminary analyses of a change context (Balogun \& Hope-Hailey, 2008). Organizational changes and justice dynamics are contextdependent and should be studied and managed accordingly (Jones \& Martens, 2009).

\section{Future Research}

Our results also suggest future avenues for research. For example, it could be of particular interest to change researchers who have incorporated justice into their study of individuals' reactions to change (see, e.g., Bernerth, Armenakis, Feild, \& Walker, 2007; Caldwell, Herold, \& Fedor, 2004; Wanberg \& Banas, 2000) to consider how other situational and individual characteristics might affect phase shifting. This could allow researchers to offer recommendations that would better capture the interaction between context and individuals' characteristics. For example, consider research on fairness, change, and cynicism: Bernerth et al. (2007) found that cynicism as an individual characteristic interacts with fairness perceptions to predict commitment to change. Research by Reichers, Wanous, and Austin (1997) established that cynical feelings about changes form following failed past change efforts. Cynicism, past organizational fairness, and phase shifting might interact in complex ways. Cynical individuals who have negative perceptions of past organizational fairness are less likely to revisit their (most likely negative) overall justice judgments because they probably suspect the change process to be fraught with self-serving motives and politics. By the same token, those same individuals, when they have positive overall justice perceptions, are more likely, in times of change, to enter into a new judgment phase because of their disposition to suspect unfair change practices.

Finally, to further understand the nature and consequences of phase shifting on justice reasoning, future research could benefit from a deeper consideration of cognitive processes (Evans, 2008; Jones \& Skarlicki, 2013). For instance, Evans and Stanovich (2013) posited that type 1 cognitive processes, such as justice heuristic judgments (or use phase, in FHT terms), are rapid autonomous processes, assumed to yield default responses unless impacted by distinctive higher-order reasoning processes, such as those triggered by perceiving a phase-shifting event.
Distinctive features of type 2 processing include support for hypothetical thinking and heavy load on working memory. Integrating such work into the exploration of justice dynamics could yield interesting insights for justice scholars. For example, while certain factors increase the likelihood of heuristic justice judgments to be recomputed through type 2 cognitive processes, other situational characteristics may reduce the probability of this actually occurring. For instance, dual-process research has established that under conditions of stress, individuals tend to rely more on type 1 cognitive processing (Porcelli \& Delgado, 2009). Pfister and Böhm (2008) proposed that specific emotions impact cognitive processes. Specifically, they argued that fear triggers rapid choices, which evokes a predominance of type 1 cognitive process. Therefore, employees who experience heightened levels of stress and fear are more likely to rely on type 1 cognitive process. This finding hints at the presence of three-way interaction among justice judgments, phase-shifting perceptions, and specific emotional state, notably those characterized by stress and fear.

\section{Limitations}

Of course, there are limitations to this research. This study is based on data collected through selfreport questionnaires from a single source, and thus might suffer from common-method and same-source biases. Although we used a time-lagged panel design, which limits these risks, it does not eliminate them. The timing of the data collection is also a limitation. Certain organizational constraints limited aspects of the data collection process. We collected the first wave of data shortly after the announcement of the merger. It is possible that during the few days after the announcement and prior to the data collection, individuals began to question whether their relationship with the company might change, and for some this may have begun the phase-shifting process before the time 1 data collection. Similarly, the organization limited our data collection to two time periods. Thus, at time 2 we assessed both antecedents of phase shifting and phase shifting itself. Ideally, we would have been able to separate the collection of these variables.

Additionally, the specificity of a change context and its strategic orientation (i.e., an international merger) limits the generalizability of the results. However, M\&As represent an important class of strategic movements and were therefore deemed important to study. Our model also considers only 
relatively simple relationships among our variables. Interaction effects among individual traits and situational variables are promising avenues of inquiry to better understand and influence individuals' justice perceptions and reactions to change.

Several measurement-related issues also exist. Given space limitations in the survey, we relied on a number of single-item measures. Although singleitem measures are generally not preferred, single items can be reliable and valid, particularly if the concept to be measured is tight and unequivocal (Wanous, Reichers, \& Hudy, 1997). We believe that this is the case for the predictors of phase-shifting perceptions. Additionally, the lack of established measures led us to develop a two-item measure based on Lind's work (2001). Although we believe the dichotomous assessment of phase shifting best fits the construct (and the supplemental experiment described in note 3 supports this conceptualization), we began with a continuous measure and converted this to a dichotomized assessment. This raises questions about our choices regarding how to categorize individuals into the Perceived Phase Shifting/No Perceived Phase Shifting categories. Specifically, we categorized individuals who reported phase shifting on either of the two items into the Perceived Phase Shifting category. Additionally, we categorized individuals who responded "neither agree or disagree" into the No Perceived Phase Shifting category. We believe this is appropriate, and our analysis of the distribution of responses (DeCoster, Iselin, \& Gallucci, 2009) supports this decision. However, one might argue that these individuals should be excluded to provide "purer" assessment of the Perceived Phase Shifting or No Perceived Phase Shifting categories. ${ }^{5}$ Unfortunately, our sample is not large enough to allow us to analyze the data in this way. Thus, this limitation should be considered when evaluating the results.

\section{CONCLUSION}

Despite the broad range of research that has utilized FHT (Lind, 2001), little empirical research has directly examined the influence of phase shifting on the relationship to justice judgments over time. By conceptualizing FHT as a form of dual-process theory and phase shifting as a perceptual phenomenon that can be predicted by individual and situational variables, this study provides a foundation for future research on FHT, phase shifting, and justice judgments over time.

\footnotetext{
${ }^{5}$ We thank an anonymous reviewer for this insight.
}

\section{REFERENCES}

Ambrose, M., \& Schminke, M. 2009. The role of overall justice judgments in organizational justice research: A test of mediation. The Journal of Applied Psychology, 94: 491-500.

Ambrose, M. L., Wo, D. X. H., \& Griffin, M. D. 2015. Overall justice: Past, present, and future. In R. Cropanzano \& M. L. Ambrose (Eds.), The Oxford University Press handbook of justice in the workplace: 109-135. Oxford, U.K.: Oxford University Press.

Armeneikis, A., Fredenberger, W., Cherones, L., Feild, H., Giles, W., \& Holley, W. 1995. Symbolic actions used by business turnaround change agents. Academy of Management Proceedings, 1995: 229-233.

Balogun, J., \& Hope-Hailey, V. 2008. Exploring strategic change (3rd ed.). Harlow: FT Prentice-Hall.

Bandura, A. 1986. Social foundations of thought and action: A social cognitive theory. Englewood Cliffs, NJ: Prentice Hall.

Bentler, P. M. 1990. Comparative fit indexes in structural models. Psychological Bulletin, 107: 238-246.

Bernerth, J. B., Armenakis, A. A., Feild, H. S., \& Walker, H. J. 2007. Justice, cynicism, and commitment: A study of important organizational change variables. The Journal of Applied Behavioral Science, 43: 303-326.

Bobocel, D. R. 2013. Coping with unfair events constructively or destructively: The effects of overall justice and self-other orientation. The Journal of Applied Psychology, 98: 720-731.

Browne, M. W., \& Cudeck, R. 1993. Alternative ways of assessing model fit. In K. A. Bollen \& J. S. Long (Eds.), Testing structural equation models: 136-162. Beverly Hills, CA: Sage.

Caldwell, S. D., Herold, D. M., \& Fedor, D. B. 2004. Toward an understanding of the relationships among organizational change, individual differences, and changes in person-environment fit: A cross-level study. The Journal of Applied Psychology, 89: 868-882.

Chiaburu, D. S., \& Harrison, D. A. 2008. Do peers make the place? Conceptual synthesis and meta-analysis of coworker effects on perceptions, attitudes, OCBs, and performance. The Journal of Applied Psychology, 93: 1082-1103.

Chreim, S. 2005. The continuity-change duality in narrative texts of organizational identity. Journal of Management Studies, 42: 567-593.

Coch, L., \& French, J. R. P, Jr. 1948. Overcoming resistance to change. Human Relations, 1: 512-532.

Colquitt, J. A., Greenberg, J., \& Zapata-Phelan, C. P. 2005. What is organizational justice? An historical overview of the field. In J. Greenberg \& J. A. Colquitt (Eds.), Handbook of organizational justice: 3-56. Mahwah, NJ: Erlbaum. 
Colquitt, J. A., Noe, R. A., \& Jackson, C. L. 2002. Justice in teams: Antecedents and consequences of procedural justice climate. Personnel Psychology, 55: 83-109.

Colquitt, J. A., et al. 2013. Justice at the millennium, a decade later: A meta-analytic test of social exchange and affect-based perspectives. The Journal of Applied Psychology, 98: 199-236.

Cropanzano, R., \& Rupp, D. E. 2003. An overview of organizational justice: Implications for work motivation. In L. W. Porter, G. Bigley \& R. M. Steers (Eds.), Motivation and work behavior (7th ed.): 82-95. New York, NY: McGraw-Hill Irwin.

DeCoster, J., Iselin, A. M. R., \& Gallucci, M. 2009. A conceptual and empirical examination of justifications for dichotomization. Psychological Methods, 14: 349-366.

De Neys, W. 2006. Automatic-heuristic and executiveanalytic processing during reasoning: Chronometric and dual-task considerations. Quarterly Journal of Experimental Psychology, 59: 1070-1100.

Elovainio, M., Kivimäki, M., \& Vahtera, J. 2002. Organizational justice: Evidence of a new psychosocial predictor of health. American Journal of Public Health, 92: 105-108.

Evans, J. S. T. B. T. 1984. Heuristic and analytic processes in reasoning. British Journal of Psychology, 75: 451-468.

Evans, J. S. T. B. T. 2006. The heuristic-analytic theory of reasoning: Extension and evaluation. Psychonomic Bulletin \& Review, 13: 378-395.

Evans, J. S. T. B. T. 2008. Dual-processing accounts of reasoning, judgment, and social cognition. Annual Review of Psychology, 59: 255-278.

Evans, J. S. T. B. T. 2010. Thinking twice: Two minds in one brain. Oxford, U.K.: Oxford University Press.

Evans, J. S. T. B. T., \& Stanovich, K. E. 2013. Dual-process theories of higher cognition: Advancing the debate. Perspectives on Psychological Science, 8: 223-241.

Fazio, R. H. 1987. Self-perception theory: A current perspective. In M. P. Zanna, J. M. Olson \& C. P. Herman (Eds.), Social influence: The Ontario symposium: 129-150. Hillsdale, NJ: Erlbaum.

Fedor, D. B., Caldwell, S., \& Herold, D. M. 2006. The effects of organizational changes on employee commitment: A multilevel investigation. Personnel Psychology, 59: $1-29$.

Fortin, M. 2008. Perspectives in organizational justice: Concept clarification, social context integration, time and links to morality. International Journal of Management Reviews, 10: 93-126.

Hausknecht, J. P., Sturman, M. C., \& Roberson, Q. M. 2011. Justice as a dynamic construct: Effects of individual trajectories on distal work outcomes. The Journal of Applied Psychology, 96: 872-880.
Holtz, B. C., \& Harold, C. M. 2009. Fair today, fair tomorrow? A longitudinal investigation of overall justice perceptions. The Journal of Applied Psychology, 94: 1185-1199.

Jones, D. A., \& Martens, M. L. 2009. The mediating role of overall fairness and the moderating role of trust certainty in justice-criteria relationships: The formation and use of fairness heuristics in the workplace. Journal of Organizational Behavior, 30: 1025-1051.

Jones, D. A., \& Skarlicki, D. P. 2005. The effects of overhearing peers discuss an authority's reputation for fairness on reactions to subsequent treatment. The Journal of Applied Psychology, 90: 363-372.

Jones, D. A., \& Skarlicki, D. P. 2013. How perceptions of fairness can change: A dynamic model of organizational justice. Organizational Psychology Review, 3: 138-160.

Judge, T. A., \& Colquitt, J. A. 2004. Organizational justice and stress: The mediating role of work-family conflict. The Journal of Applied Psychology, 89: 395-404.

Kahneman, D. 2003. A perspective on judgment and choice: Mapping bounded rationality. The American Psychologist, 58: 697.

Kahneman, D., Slovic, P., \& Tversky, A. 1982. Judgment under uncertainty: Heuristics and biases. New York, NY: Cambridge University Press.

Kernan, M. C., \& Hanges, P. J. 2002. Survivor reactions to reorganization: antecedents and consequences of procedural, interpersonal, and informational justice. The Journal of Applied Psychology, 87: 916.

Kim, T.-Y., \& Leung, K. 2007. Forming and reacting to overall fairness: A cross-cultural comparison. Organizational Behavior and Human Decision Processes, 104: 83-95.

Kline, R. B. 2005. Principles and practice of structural equation modelling. New York, NY: Guilford Press.

Leventhal, G. 1980. What should be done with equity theory? In K. Gergen, M. Greenberg \& R. Willis (Eds.), Social exchange: 27-55. New York, NY: Springer.

Lind, E. A. 2001. Fairness heuristic theory: Justice judgments as pivotal cognitions in organizational relations. In J. Greenberg \& R. Cropanzano (Eds.), Advances in organizational justice: 556-588. Stanford, CA: Stanford University Press.

Lind, E. A., \& Tyler, T. R. 1988. The social psychology of procedural justice. New York, NY: Plenum Press.

Lind, E. A., \& Van den Bos, K. 2002. When fairness works: Toward a general theory of uncertainty management. In B. Staw \& R. M. Kramer (Eds.), Research in organizational behavior, vol. 24: 181-223. Amsterdam: Elsevier Press.

Maitlis, S., \& Sonenshein, S. 2010. Sensemaking in crisis and change: Inspiration and insights From Weick (1988). Journal of Management Studies, 47: 551-580. 
Melkonian, T., Monin, P., \& Noorderhaven, N. 2011. Distributive justice, procedural justice, exemplarity, and employees' willingness to cooperate in M\&A integration processes: An analysis of the Air France-KLM Merger. Human Resource Management, 50: 809-837.

Melkonian, T., Soenen, G., \& Ambrose, M. 2015. Will I cooperate? The moderating role of informational distance on justice reasoning. Journal of Business Ethics, 137: 1-13.

Nicklin, J. M., McNall, L. A., Cerasoli, C. P., Strahan, S. R., \& Cavanaugh, J. A. 2014. The role of overall organizational justice perceptions within the four-dimensional framework. Social Justice Research, 27: 243-270.

Oreg, S. 2003. Resistance to change: Developing an individual differences measure. The Journal of Applied Psychology, 88: 680-693.

Oreg, S. 2006. Personality, context, and resistance to organizational change. European Journal of Work and Organizational Psychology, 15: 73-101.

Oreg, S., et al. 2008. Dispositional resistance to change: measurement equivalence and the link to personal values across 17 nations. The Journal of Applied Psychology, 93: 935-944.

Oreg, S., Vakola, M., \& Armenakis, A. 2011. Change recipients' reactions to organizational change: a 60-year review of quantitative studies. The Journal of Applied Behavioral Science, 47: 461-524.

Pettigrew, A. M., Woodman, R. W., \& Cameron, K. S. 2001. Studying organizational change and development: Challenges for future research. Academy of Management Journal, 44: 697-713.

Pfister, H. R., \& Böhm, G. 2008. The multiplicity of emotions: A framework of emotional functions in decision making. Judgment and Decision Making, 3: 5-17.

Porcelli, A. J., \& Delgado, M. R. 2009. Acute stress modulates risk taking in financial decision making. Psychological Science, 20: 278-283.

Reichers, A. E., Wanous, J. P., \& Austin, J. T. 1997. Understanding and managing cynicism about organizational change. The Academy of Management Executive, 11: 48-59.

Rigdon, E. E., Schumaker, R. E., \& Wothke, L. 1998. A review of interaction and nonlinear modeling. In R. E. Schumacker \& G. A. Marcoulides (Eds.), Interaction and nonlinear effects in structural equation modeling: 1-16. Mahwah, NJ: Lawrence Erlbaum.

Rodell, J. B., \& Colquitt, J. A. 2009. Looking ahead in times of uncertainty: The role of anticipatory justice in organizational change context. The Journal of Applied Psychology, 94: 989-1002.

Salancik, G. R., \& Pfeffer, J. 1978. A social information processing approach to job attitudes and task design. Administrative Science Quarterly, 23: 224-253.
Shapiro, D. L., \& Kirkman, B. L. 1999. Employees’ reaction to the change to work teams: The influence of "anticipatory" injustice. Journal of Organizational Change Management, 12: 51-66.

Shapiro, D. L., \& Kirkman, B. L. 2001. Anticipatory injustice: The consequences of expecting injustice in the workplace. In J. Greenberg \& R. Cropanzano (Eds.), Advances in organizational justice: 152-178. Lexington, MA: New Lexington.

Skarlicki, D. P., \& Rupp, D. E. 2010. Dual processing and organizational justice: the role of rational versus experiential processing in third-party reactions to workplace mistreatment. The Journal of Applied Psychology, 95: 944.

Spector, P. E. 2002. Employee control and occupational stress. Current Directions in Psychological Science, 11: 133-136.

Stanovich, K. E. 1999. Who is rational? Studies of individual differences in reasoning. Mahwah, NJ: Erlbaum.

Stanovich, K. E. 2009. Distinguishing the reflective, algorithmic, and autonomous minds: Is it time for a triprocess theory? In J. S. B. T. Evans \& K. Frankish (Eds), In two minds: Dual processes and beyond: 55-88. Oxford, U.K: Oxford University Press.

Stanovich, K. E. 2011. Rationality and the reflective mind. New York, NY: Oxford University Press.

Strack, F., \& Deutsch, R. 2004. Reflective and impulsive determinants of social behavior. Personality and Social Psychology Review, 8: 220-247.

Thompson, V. A., Turner, J. A. P., \& Pennycook, G. 2011. Intuition, reason, and metacognition. Cognitive Psychology, 63: 107-140.

Tost, L. P., \& Lind, E. A. 2010. Sounding the alarm: Moving from system justification to system condemnation in the justice judgment process. In E. Salas (Ed.) Research on managing groups and teams, vol. 13: 3-27. Bingley, U.K.: Emerald Group Publishing.

Van den Bos, K., Vermunt, R., \& Wilke, H. A. M. 1997. Procedural and distributive justice: What is fair depends more on what comes first than on what comes next. Journal of Personality and Social Psychology, 72: 95-104.

Van den Bos, K., \& Lind, E. A. 2002. Uncertainty management by means of fairness judgments. In M. P. Zanna (Ed.), Advances in experimental social psychology, vol. 34: 1-60. San Diego, CA: Academic Press.

Van den Bos, K., Lind, E. A., \& Wilke, H. A. M. 2001. The psychology of procedural justice and distributive justice viewed from the perspective of fairness heuristic theory. In R. Cropanzano (Ed.), Justice in the workplace. From theory to practice, vol. 2: 49-66. Mahwah, NJ: Erlbaum. 
Wanberg, C. R., \& Banas, J. T. 2000. Predictors and outcomes of openness to changes in a reorganizing workplace. The Journal of Applied Psychology, 85: 132-142.

Wanous, J. P., Reichers, A. E., \& Hudy, M. J. 1997. Overall job satisfaction: How good are single-item measures? The Journal of Applied Psychology, 82: 247-252.

\section{$M$}

Guillaume Soenen (soenen@em-lyon.com) is an associate professor and director of the Cognitions, Behaviors and Transformations research center at Emlyon Business School. He holds the APICIL Chair of Health \& Performance at Work. He received his $\mathrm{PhD}$ in management from HEC Paris. His research interests include organizational justice, organizational change, and the interplay of health, wellbeing, and performance.

Tessa Melkonian (melkonian@em-lyon.com) is professor of organizational behavior at Emlyon Business School. She received her $\mathrm{PhD}$ in management from the University of Paris II. Her research interests include the role of justice and exemplarity on employees' reactions to change, determinants of employees' cooperation in M\&A contexts, and collective performance in extreme teams.

Maureen Ambrose (mambrose@ucf.edu) is the Gordon J. Barnett professor of business ethics at the University of Central Florida. She received her $\mathrm{PhD}$ in industrial/ organizational psychology from the University of Illinois at Urbana-Champaign. Her research interests include organizational fairness, gratitude, ethics, and workplace deviance.

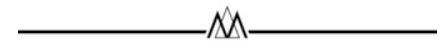

\section{APPENDIX A}

\section{MEASURES}

\section{Phase-shifting perceptions}

1. This change makes me reconsider my relationship with the organization.

2. The fairness of activities related to the change is very different from what I have come to expect from this company.

Answer format: $1=$ strongly disagree; $4=$ neither agree nor disagree; 7 = strongly agree

\section{Overall justice}

Regarding the company and the management, please indicate the extent to which you agree or disagree with the following statements.
1. In general, I can count on this organization to be fair.

2. In general, the treatment I receive around here is fair.

3. Overall, I am treated fairly by my organization.

Answer format: 1 = strongly disagree; $4=$ neither agree nor disagree; 7 = strongly agree

\section{Anticipatory justice facets}

The following questions refer to the outcomes (e.g., pay, bonuses, promotions, opportunities for training, etc.) you anticipate receiving personally as consequences of this change. To what extent:

1. Will your change outcomes reflect the effort you will put into your work (additional workload, adaptation to new systems or new schedules, etc.)?

2. Will your change outcomes be appropriate for the work you will complete?

3. Will your change outcomes reflect what you will contribute to the organization?

4. Will your change outcomes be justified, given your performance?

Answer format: $1=$ to a small extent; $3=$ to a moderate extent; $5=$ to a great extent

The following questions refer to the procedures you anticipate will be used to implement this change. To what extent:

1. Will you be able to express your views and feelings?

2. Will you have influence over the outcomes?

3. Will the decision-making processes be applied consistently?

4. Will the decision-making processes be free of bias?

5. Will the decisions be based on accurate information?

6. Will you be able to appeal the change outcomes?

7. Will the decision-making processes uphold ethical and moral standards?

Answer format: $1=$ to a small extent; $3=$ to a moderate extent; $5=$ to a great extent

The following questions refer to how you anticipate your supervisor will treat you during this change. To what extent:

1. Will your supervisor treat you with dignity?

2. Will your supervisor treat you with respect?

3. Will your supervisor refrain from improper remarks or comments?

4. Will the decision-making processes be free of bias?

5. Will your supervisor be candid in his or her communication with you?

6. Will your supervisor explain his or her decisions thoroughly?

7. Will your supervisor communicate the change details in a timely manner? 
8. Will explanations of the decisions be reasonable?

9. Will your supervisor tailor his or her communication to your specific needs?

Answer format: $1=$ to a small extent; $3=$ to a moderate extent; 5 = to a great extent

\section{Magnitude of change}

1. Compared to how you were working before, this change is...

Answer format: $1=$ not really a change; $2=$ a minor change; $3=$ an important change; $4=$ a fundamental change

\section{Managerial exemplarity}

1. So far, my supervisor has behaved in accordance with what is expected from the rest of the employees, notably in terms of cooperation behaviors.

Answer format: 1 = strongly disagree; 4 = neither agree nor disagree; 7 = strongly agree

\section{Social support}

1. Do your colleagues support the change?

Answer format: 1 = yes, clearly; 2 = overall yes; $3=$ yes, somewhat; $4=$ not really; $5=$ definitely not

\section{Dispositional resistance to change}

Please indicate the extent to which you agree or disagree with the following statements.

1. Igenerally consider changes to be a negative thing.

2. I'd take a routine day over a day full of unexpected events any time.

3. I like to do the same old things rather than try new and different ones.

4. Whenever my life forms a stable routine, I look for ways to change it.

5. I'd rather be bored than surprised.

6. If I were to be informed of a change that would significantly transform my life, I would likely feel stressed out.

7. When I am informed of a change of plans, I tense up a bit.

8. When things don't go according to plan, it stresses me out.

9. I would probably feel uncomfortable if my employer was to change employees' evaluation criteria even if I thought I'd do just as well without doing any extra work.

10. Changing plans seems like a real hassle to me.

11. Often, I feel a bit uncomfortable even about changes that may potentially improve my life.

12. When someone pressures me to change something, I tend to resist it even if I think the change may ultimately benefit me.

13. I sometimes find myself avoiding changes that I know will be good for me.

14. I often change my mind.

15. I don't change my mind easily.

16. Once I've come to a conclusion, I'm not likely to change my mind.

17. My views are very consistent over time.

Answer format: 1 = strongly disagree; 6 = strongly agree

\section{Tenure}

1. How long have you been working for [the company]?

Answer format: in years

\section{Entity}

1. In which entity do you work?

Answer format: 1 = company A; $2=$ company B

\section{Change favorableness}

1. On a personal level, is this change a good thing for you?

Answer format: 1 = yes, clearly; 2 = overall yes; 3 = yes, somewhat; $4=$ not really; $5=$ definitely not

\section{Past organizational fairness}

1. In the past, has this organization managed organizational changes in a fair manner?

Answer format: 1 = yes, clearly; 2 = overall yes; 3 = yes, somewhat; $4=$ not really; $5=$ definitely not

\section{Experience with change}

1. Throughout your career, your personal experience with organizational change has been:

Answer format: 1 = very negative; 2 = negative; 3 = neutral; $4=$ positive; 5 = very positive 